\title{
Membranous aplasia cutis congenita in trisomy 18
}

\author{
Francisco Cammarata-Scalisi ${ }^{1 *}\left(\mathbb{D}\right.$, Andrea Diociaiuti $^{2}$, Blanca de Guerrero ${ }^{3}$, Colin Eric Willoughby ${ }^{4}$ and \\ Michele Callea ${ }^{5^{*}}$
}

\begin{abstract}
Background: Aplasia cutis congenita (ACC) is a rare congenital condition characterized by the absence of skin layers and sometimes other underlying structures, in a localized or widespread area. The exact etiopathogenesis is not yet completely understood. Membranous ACC (MACC) also described as bullous or cystic ACC is a clinical subtype of ACC, covered with a membranous or glistening surface, and appears as a flat scar. There are less than 20 cases reported in the literature. It has been proposed an abortive form of a defective closure of the neural tube. On the other hand, the trisomy 18 is a chromosomal abnormality characterized by a broad clinical spectrum and the presence of defective closure of the neural tube.
\end{abstract}

Case presentation: We report on an 18-months-old Venezuelan boy, who presented on the parietal scalp a distinctive localized MACC appearing as an oval lesion covered with a membranous surface, characterized by the absence of hairs and the presence of a sharp hair collar. The karyotype in peripheral blood was 47,XY,+ 18 .

Conclusions: This is the second case report of ACC in trisomy 18 and reinforces the interpretation of a nonfortuitous association as well as of a defective closure of the neural tube as pathogenetic mechanism. The case highlights the importance of examining for dermatological alterations such as ACC in cases of chromosomopathy.

Keywords: Aplasia cutis congenita, Membranous aplasia cutis congenita, Trisomy 18, Defective closure of the neural tube

\section{Background}

Aplasia cutis congenita (ACC) is a rare congenital condition characterized by the absence of skin layers and sometimes other underlying structures, in a localized or widespread area [1-3]. The exact etiology of ACC is not completely understood. Several factors have been proposed as possible causes, e.g., vascular disruption, thrombotic events, trauma, amniotic defects, chromosomal abnormalities or gene mutations, ectodermal dysplasia, defective closure of the neural tube, and

\footnotetext{
*Correspondence: francocammarata19@gmail.com; mcallea@gmail.com ${ }^{1}$ Pediatrics Service, Regional Hospital of Antofagasta, Antofagasta, Chile ${ }^{5}$ Unit of Dentistry, Bambino Gesù Children Hospital and Research Institute, Rome, Italy

Full list of author information is available at the end of the article
}

teratogenic events such as intrauterine infections, or drugs and medications during pregnancy [4-6].

The most common lesion location of ACC is the scalp in $70 \%[7,8]$; however, any skin site can be affected [7]. The estimated incidence of ACC is approximately $0.5-3$ in 10,000 newborns $[2,5]$, regardless of gender or ethnicity [5]. The clinical appearance of ACC is heterogeneous and it can be associated with various systemic congenital anomalies. However, in most cases, it is just a sporadic defect and the cause is unknown $[2,3]$.

Membranous ACC (MACC) also described as bullous or cystic ACC is a clinical subtype of ACC, covered with a membranous or glistening surface $[3,8]$, and appears as a flat scar. There are less than 20 cases reported in the literature [3]. A review of 17 MACC cases identified that all lesions were located on the skull with the

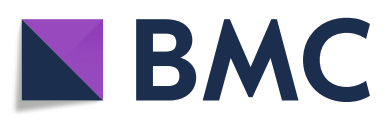

(c) The Author(s). 2020 Open Access This article is licensed under a Creative Commons Attribution 4.0 International License, which permits use, sharing, adaptation, distribution and reproduction in any medium or format, as long as you give appropriate credit to the original author(s) and the source, provide a link to the Creative Commons licence, and indicate if changes were made. The images or other third party material in this article are included in the article's Creative Commons licence, unless indicated otherwise in a credit line to the material. If material is not included in the article's Creative Commons licence and your intended use is not permitted by statutory regulation or exceeds the permitted use, you will need to obtain permission directly from the copyright holder. To view a copy of this licence, visit http://creativecommons.org/licenses/by/4.0/ The Creative Commons Public Domain Dedication waiver (http://creativecommons.org/publicdomain/zero/1.0/) applies to the data made available in this article, unless otherwise stated in a credit line to the data. 
majority on the vertex or parietal scalp, ranging in number from 1 to 7 lesions, and frequently associated with bone defects 6/17 [9]. We present the second case of ACC associated with trisomy 18 to emphasize that the association might not be fortuitous and that the pathogenesis may reflect a defective closure of the neural tube.

\section{Case report}

An 18-months-old Venezuelan boy, first case of ACC in the family, born from nonconsanguineous healthy parents, (44-year-old mother at the time of conception). The child was delivered from the sixth mother's pregnancy. The prenatal course was complicated with a threatened abortion evidenced as transvaginal bleeding due to a uterine myoma. The infant was born at 41 weeks by caesarean section and the birth weight was $1830 \mathrm{~g}$, (SD - 3.7), height $40 \mathrm{~cm}$ (SD - 8.1), and head circumference $31 \mathrm{~cm}$ (percentile <3). Apgar test was 6 and 8 points at the first and fifth minute respectively.

At 8 months of age the infant was $4570 \mathrm{~g}$ in weight (SD - 5.3), size $56 \mathrm{~cm}$ (SD -0.4), head circumference $40.5 \mathrm{~cm}$ (percentile <3). The normotensive anterior fontanelle was of $2 \times 2 \mathrm{~cm}$ with high implantation of the hair and an oval lesion covered with a membranous surface of $1.3 \times 1.1 \mathrm{~cm}$ on the parietal scalp characterized by absence of hair and presence of a sharp hair collar (Fig. 1). Transfontanellar sonography showed no abnormalities. Facial dysmorphism, prominence at the level of the metopic suture, wide frontal region with hypertrichosis, convergent bilateral strabismus, depressed nasal bridge and anteverted nostrils (Fig. 2), hypoplasia and proximal insertion of thumb with equine varus right foot and valgus left foot were present. Moreover, the infant presented heart sounds with systolic murmur grade III/ VI, and right cryptorchidism.

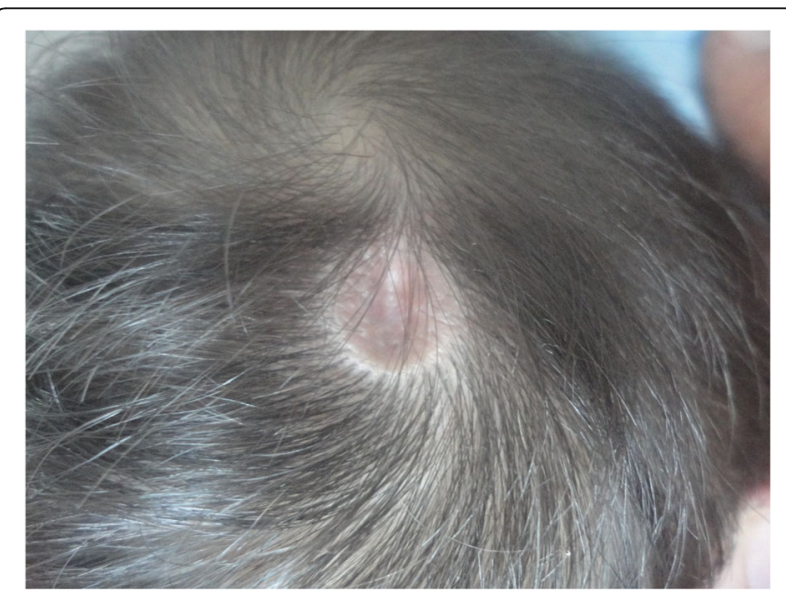

Fig. 1 MACC oval lesion covered with a membranous surface

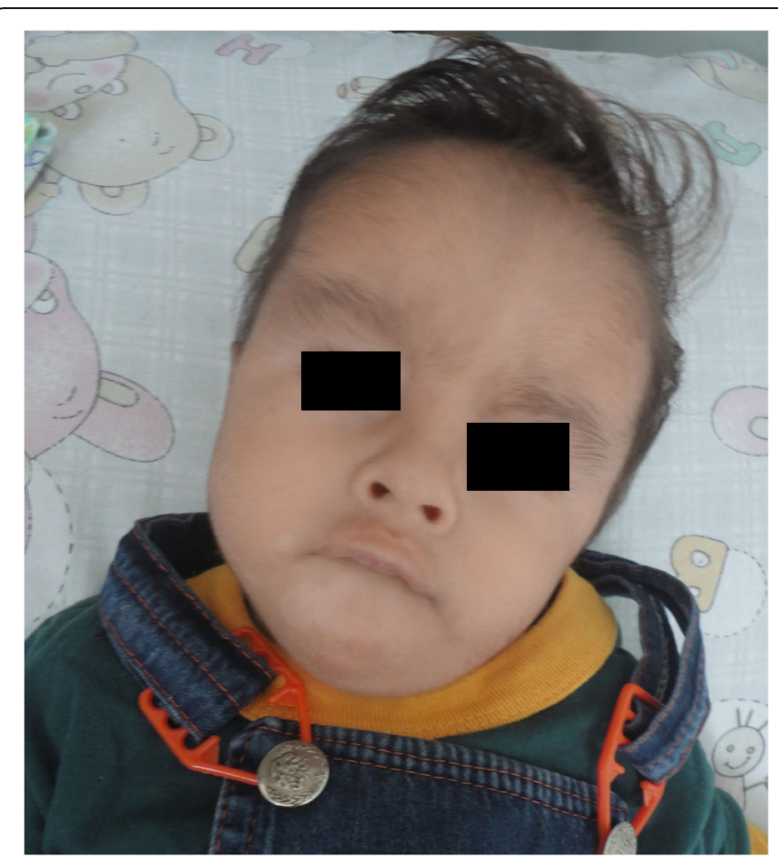

Fig. 2 Prominence at the level of the metopic suture, wide frontal region with hypertrichosis and anteverted nostrils

Echocardiography showed ostium secundum type interatrial communication, interventricular communication, and persistent arterial duct with hemodynamic repercussion. The karyotype in peripheral blood was 47 , XY,+ 18, metaphases studied 30 .

\section{Discussion and conclusions}

Drolet et al. [10]. have proposed that MACC is an abortive form of a defective closure of the neural tube and that the hair collar sign should be regarded as a relatively specific marker for this defect [11]. Associated findings were hydrocephaly, meningeal arteriovenous fistula, epilepsy, spasticity, primary optic nerve atrophy, corneal lipodermoid changes, cornea scleralization, cleft palate, hemangioma and nevus flammeus [8]. More recently two features have been reported as more specific or pathognomonic "hair bulbs arranged radially along hair-bearing margins" [12], and the "golf club set" on trichoscopy [3].

The diagnosis of MACC is essentially clinical, and a biopsy is usually not needed. MACC can be visualized on prenatal ultrasonography as a smooth cystic lesion without flow. Ultrasonography of the lesion and transfontanellar ultrasonography can rule out skull defects or cerebral alterations. Conservative therapy is the option of choice [3, 8].

Trisomy 18 is a chromosomal abnormality most of the times incompatible with life and a limited survival. The clinical spectrum is broad, more than 130 different abnormalities having been described in these patients 
and the presence of defective closure of the neural tube among patients with trisomy 18 is not uncommon [13]. In a previous study on a series of mosaic trisomy 18 , we did not find ACC in five cases studied [14].

Genetics plays a pathogenetic role in ACC as indicated by its occurrence in other chromosomopathies (Table 1 , Supplementary), as well as with mutations such as the ribosomal GTPase BMS1 gene [15]. In addition, familial cases of ACC have been reported with an autosomal dominant transmission [16].

ACC and trisomy 18 have been described first in an Indian newborn [17], who died 5 days after birth. The occurrence of an additional case would support that the association is not fortuitous and that the pathogenesis may reflect a defective closure of the neural tube. Our child was 18 months old at the time of detection of the chromosomal abnormality. The long survival indicates a mild-moderate form with most malformations correctable.

The case highlights the importance of examining the entire integument to search for dermatological alterations such as ACC and making a complete assessment of multisystemic lesions, especially in cases of a mild form of chromosomopathy and a long survival.

\section{Supplementary information}

Supplementary information accompanies this paper at https://doi.org/10. 1186/s13052-020-00885-6.

Additional file 1 Supplementary file 1 Table 1. Chromosomal alterations described in the ACC, divided into numerical and structural.

\section{Abbreviations}

ACC: Aplasia cutis congenita; MACC: Membranous aplasia cutis congenita

\section{Acknowledgements}

We would like to thank Rosalia Gumina of the University of The Andes for her support with the literature review.

\section{Authors' contributions}

CSF collected all data from the clinical records, drafted the manuscript, and revised the manuscript. $A D$ and $C E W$ revised the manuscript. $M C$ drafted the manuscript, and revised the manuscript. The authors approved the final manuscript as submitted and agree to be accountable for all aspects of the work.

\section{Funding}

The author(s) received no financial support for the research, authorship, and/ or publication of this article.

\section{Availability of data and materials}

The datasets used and/or analyzed during the current study are available from the corresponding author on reasonable request.

\section{Competing interests}

The author(s) declared no potential conflicts of interest with respect to the research, authorship, and/or publication of this article.

\section{Author details}

${ }^{1}$ Pediatrics Service, Regional Hospital of Antofagasta, Antofagasta, Chile. ${ }^{2}$ Dermatology Unit, Bambino Gesù Children's Hospital, IRCCS, Rome, Italy. ${ }^{3}$ Foundation Child Development Center, Mérida, Venezuela. ${ }^{4}$ Biomedical Sciences Research Institute, Ulster University, Northern Ireland, UK. ${ }^{5}$ Unit of Dentistry, Bambino Gesù Children Hospital and Research Institute, Rome, Italy.

Received: 28 March 2020 Accepted: 19 August 2020

Published online: 27 August 2020

\section{References}

1. Snyder ML, Ilyas H. Type $V$ aplasia cutis congenita with fetus papyraceus. JAAD Case Rep. 2019;5(4):303-5.

2. Kim J, Kim J, Lee M, Huh ER, Lim J, Park Kl, et al. A case of aplasia cutis congenita with widespread multifocal skin defects without extracutaneous abnormalities. Acta Derm Venereol. 2019;99(3):343-4.

3. Cutrone M, Grimalt R. The trichoscopic "golf Club set" sign for bullous aplasia cutis congenita. Skin Appendage Disord. 2018;4(4):320-2.

4. Magliah T, Alghamdi F. Aplasia cutis congenita: a case report. Case Rep Dermatol. 2018;10(2):182-6.

5. Mugarab-Samedi V, Lodha A, ElSharkawy A, Al Awad E. Aplasia cutis congenita as a result of interstitial laser therapy for fetal reduction in monochorionic twins: conservative approach and outcome. Int J Surg Case Rep. 2017:41:68-70.

6. Brzezinski P, Pinteala T, Chiriac AE, Foia L, Chiriac A. Aplasia cutis congenita of the scalp-what are the steps to be followed? Case report and review of the literature. An Bras Dermatol. 2015;90(1):100-3.

7. Blionas A, Giakoumettis D, Antoniades E, Drosos E, Mitsios A, Plakas S, et al. Aplasia cutis congenita: two case reports and discussion of the literature. Surg Neurol Int. 2017;8:273

8. Lozano-Masdemont B. A case of membranous aplasia cutis congenita and dermoscopic features. Int J Trichology. 2017:9(1):33-4.

9. Colon-Fontanez F, Fallon Friedlander S, Newbury R, Eichenfield LF. Bullous aplasia cutis congenita. J Am Acad Dermatol. 2003:48(5 Suppl):S95-8.

10. Drolet B, Prendiville J, Golden J, Enjolras O, Esterly NB. 'Membranous aplasia cutis' with hair collars. Congenital absence of skin or neuroectodermal defect? Arch Dermatol. 1995;131(12):1427-31.

11. Held I, Rose C, Hamm H, Fölster-Holst R. The hair collar sign - a possible indication of cranial dysraphism. J Dtsch Dermatol Ges. 2011;9(2):136-8.

12. Rakowska A, Maj M, Zadurska M, Czuwara J, Warszawik-Henzel O, Olszewska $M$, et al. Trichoscopy of focal alopecia in children - new trichoscopic findings: hair bulbs arranged radially along hair-bearing margins in aplasia cutis congenita. Skin Appendage Disord. 2016:2(1-2):1-6.

13. Rosa RF, Trevisan P, Rosa RC, Lorenzen MB, Zen PR, Oliveira CA, et al. Trisomy 18 and neural tube defects. Pediatr Neurol. 2013:49(3):203-4.

14. Cammarata-Scalisi F, Lacruz-Rengel MA, Araque D, Da Silva G, Avendaño A, Callea M, et al. Trisomía 18 en mosaico. Serie de casos. Arch Argent Pediatr. 2017;115(3):e183-6.

15. Marneros AG. BMS1 is mutated in aplasia cutis congenita. PLoS Genet. 2013; 9(6):e1003573.

16. Yağci-Küpeli B, Çağlar K, Büyük S, Balci S. Autosomal dominant aplasia cutis in three generations and one case with preaxial polydactyly in the last generation. Genet Couns. 2011;22(1):55-61.

17. Mishra S, Agarwalla SK, Praharaj BR, Potpalle DR. Edward syndrome with aplasia cutis congenita: a rare case report. IJNMR. 2014;2(3):7-9.

\section{Publisher's Note}

Springer Nature remains neutral with regard to jurisdictional claims in published maps and institutional affiliations. 